\title{
Incentive Mechanism for Customer Collaboration in Product Development: An Exploratory Study
}

\author{
Chunguang Gu, Yang Yang \\ School of Public Policy and Management, University of Chinese Academy of Sciences (China)
}

13811441128@126.com,yangyang310@mails.ucas.ac.cn

Received: July 2015

Accepted: September 2015

\section{Abstract:}

Purpose: The purpose of this paper provides some appropriate incentive factors for customers who collaboration in product development, and analyzes the mechanism and degree of these incentive factors influence on customer's positivity and working efforts.

Design/methodology/approach: This paper first proposes the economic incentives and non-economic incentives according to the characteristics of customer collaborative product development. Then the firm and customer's objective function and constraints are determined based on their income and costs that produce in the process of customer collaborative product development. On this basis, this study then analyzes the relationship between the incentive factors and customer's positivity and working efforts.

Findings: The results show that: the fixed salary shows no motivational effect but basic guarantee. The performance salary has more influence on promoting customers' efforts than the efforts of helping other customers. The team share incentive affects both effort levels equally. The better spiritual incentive, the higher firm's effort level, the better innovative environment, and the more motivate customer collaboration in product development. 
Practical implications: The results of this paper can help firms to understand the influence of different incentive factors, and offer them with references to determine incentive factors and its degree.

Originality/value: This paper provides a comprehensive incentive mode, which including economic incentive factors and non-economic incentive factors. Moreover, the paper provides an insight on the relationship between these incentive factors and customer's positivity and working efforts.

Keywords: product development, customer collaboration, economic incentive, non-economic incentive

\section{Introduction}

With the increasing competition in markets today, firms are gradually recognizing the importance of being better and faster to develop new products than their competitors, which can help them to obtain market competitive advantage and earn more revenue returns (Büyüközkan \& Arsenyan, 2012). However, the rapid changes of external environment, such as economic and technology environment, force firms to rely on not only its own resources but also external knowledge, resources and technology. Customers as one of the most important external resources (Von Hippel, 2005; Yu, Yu, Xing \& Li, 2014), it is valuable to integrate them into new product development. Customer collaboration can help firms to get customers' knowledge and ability about product development, and achieve the target of improving the quality and market satisfaction of new products (Faems, Van Looy \& Debackere, 2005; Miotti \& Sachwald, 2003; Nieto \& Santamaría, 2007).

However, customer collaboration in product development is not always positive and voluntary. There are barriers for them to provide their knowledge, expertise, and experience, which related to product development (Lin, 2007). There are two main reasons. One is customers regard their knowledge, information and capacity, as the important capital and foundation to create value. This situation is more obvious when their knowledge and expertise is critical to product development (Ba, Stallaert \& Whinston, 2001; Baldwin, Hienerth \& Von Hippel, 2006). Secondly, customers need to take time, effort, and even money when they collaborating with firms to develop new products (Bartl, Fuller, Muhlbacher \& Ernst, 2012; Davenport \& Prusak, 2000). Therefore, customers will not contribute their knowledge, expertise, and experience to the firm for free. For the firms who want to integrate customers in product development and increase customer's positivity and working effort during the process of product development, it is important for them to provide appropriate incentive to customers. In order to motivate customers to collaborate in product development, currently researches propose some incentive factors. For example, Amabile, Conti, Coon, Lazenby and Herron (1996) deemed that it is 
important to provide certain financial rewards and other incentives to customers, because the good and long-term cooperative relationships with customers have a major influence on the firm. Vargo and Lusch (2004) proposed multiple incentives, including financial rewards, move up the quality service, and experience new product with a high priority etc. Besides financial rewards and tangible incentives, intangible and nonmonetary incentives are also important to improve customer's positivity (Kaiser \& Müller-Seitz, 2008; Von Hippel, 2005). For example, self-worth promoting, enjoyable experience and learning of knowledge and skills etc. are the common methods. Füller (2010) deemed that the potential factors, such as communication between customers and the firm, the challenge of solving new problems, and the change of cognition, can also become the incentive factors that motivate customers integrating in product development.

The researchers above have recognized the important of customer incentive during the process customer collaborative product development and proposed some incentive factors. However, little is known about how and the degree of these incentive factors influence customer's positivity and working efforts. The purpose of this study is to identify two kinds of incentive factors, and develop a model to analyze the manner and degree of these incentive factors influence on customer's positivity and working efforts in the process customer collaborative product development. The analysis results can help firms to understand the influence mechanism and degree of different incentive factors, and offer them with references to determine incentive factors and its degree.

After proposing and analyzing incentive factors in section 2, section 3 develops an incentive model and determines the objective function and constraints of customer and the firm. Section 4 discusses the influence of incentive factors on the positivity and working efforts of customer collaboration. The final Section concludes the paper.

\section{Analysis of Incentive Factors}

During the process of customer collaborative product development, customers using their unique knowledge, experience, and expertise to develop new products under the collaborative environment of network. (Yang, Guo, Yin, Wang \& Zhang, 2008) customers who integrating in product development can be mainly divided into several types, respectively are demanding customer, lead uses, reference customer, first buyer, and launching customer (Kausch, 2007). Moreover, the same type of customers related with each other and form an innovation team (Brockhoff, 2003). There are two important points for the customers in the innovation team. The one is customers participate in and undertake parts of product development tasks based on their knowledge, expertise, and skills. Secondly, customers should cooperate and help with other customers in the innovation team to solve the problems jointly in the process of developing new products. Product development is a complicated systematic project, which 
consist of a number of tasks. As for the tasks with higher requirements and greater difficulty, customers are not capable of independently accomplishing the task, and it needs mutual collaboration among customers for the completion of these tasks. The cooperation between customers is conducive to improve the efficiency of the customers themselves as well as the whole innovation team in the product development.

Customers in the innovation team develop new products, not only seek to obtain economic returns, but also pay attention to the realization of self-value, the contentment of the interest, as well as the enjoyment of the sense of achievement after settling the difficulty in the process of product development (Greer \& Lei, 2012). For example, customers can utilize the toolkits of Apple Corp to develop the App application software according to the needs of their own interest (Zhang \& Zhang, 2012). Moreover, they can sell their developed software in App Store

As for the characteristics of customers who collaboration in product development, it works out to be ineffective in encouraging customers only by the traditional way of economic incentives. Therefore, this study proposes the customer incentive mode by combining the economic incentives and non-economic incentives. Thereinto, the economic incentives include the fixed salary, the performance salary, and the team share. Moreover, the performance salary can stimulate the enthusiasm and initiative of the customers to collaborate in product development. The team share is carried out according to the overall performance of the innovation team. By the cooperation of the customers, it can form a synergistic effect in the aspect of the increasingly improved performance of the innovation team and the higher team share. In view of the non-economic incentive factors, this study investigates two main forms. Firstly, the firm provides a good environment for the customers who collaboration in product development to improve the product development performance. For example, good product development atmosphere, the informationalization platform for product development, product development tool and training. In this way, it can facilitate the customers to participate in the product development activities. Moreover, it also can be helpful for customers to gain experience in the pleasant working atmosphere. Secondly, the non-economic incentives can be the spiritual motivation for the customers. For example, promoting the customers to realize selfvalue and self-satisfaction, offering priority of experience right in the new products and supporting the customers with trust and care by the enterprises, which can motivate the working enthusiasm of the customers. 


\section{Model}

\subsection{The Customer's Objective}

Consider an innovation team with $n$ customers. Each of them is supposed to be homogeneous and pursuing of self-utility maximization (Auriol, Friebel \& Pechlivanos, 2002).

Customers' efforts for the product development can be divided into two aspects. One is the efforts of collaborating with the form to complete product development tasks. Moreover, the effort degree of the $i$ th customer is represented by $e_{i}$. Another is the efforts of helping other customers to complete their tasks. Suppose $m_{i j}$ denotes the effort degree of the $i$ th customer helping the $j$ th customer. The output function of the $i$ th customer can be described as $\pi\left(x_{i}\right)=e_{i}+\sum_{i \neq j} m_{j i}+\varepsilon_{i}$. Where $\varepsilon_{i}$ is the exogenous random variable complying with the normal distribution, and $\varepsilon_{i} \sim N\left(0, \sigma^{2}\right)$.

Customers have to incur certain costs and expenses when they make efforts for themselves and for other customers during the process of product development. This study names the costs and expenses of customers paid out in product development as effort costs. The effort costs of a customer not only cover the effort costs of his own, but also the effort costs of helping other customers, which including time consuming and energy exhaustion etc. This study assumes that it is independent between various efforts. on this basis, we can calculate the effort costs of the $i$ th customer as $C_{i}=\frac{1}{2} a e_{i}^{2}+\frac{1}{2} a \sum_{i \neq j} m_{i j}^{2}$. Thereinto, $\frac{1}{2} a e_{i}^{2}$ is the effort cost of his own (Wei, Yu, Wang \& Lai, 2007). While $a$ is the effort cost coefficient, which is negative correlation with the ability level of the customer. $\frac{1}{2} a \sum_{i \neq j} m_{i j}^{2}$ is the effort cost of helping other customers.

The firm proposes economic incentives and non-incentives for the customers to motivate them to make more efforts for product development. As for economic incentives, suppose the salary incentive provided by the firm including the fixed salary and the performance salary. Furthermore, $s$ denotes the fixed salary and each customer is equal. The performance salary is $\alpha \pi\left(x_{i}\right)$, and $\alpha$ represent the coefficient of the performance salary to stand for the individual incentive intensity. The team share is $\beta \sum_{t=1}^{n} \pi\left(x_{t}\right)$, where $\beta$ denotes as the coefficient of the team share to represent the team incentive intensity. Suppose the firm adopts economic incentive to the customers in the form of the linear contract (Holmstrom \& Milgrom, 1987), and then we can determine the economic incentive income of the $i$ th customer is $s+\alpha \pi\left(x_{i}\right)+\beta \sum_{t=1}^{n} \pi\left(x_{t}\right)$. 
As for the non-economic incentives, the first one is the firm provides a good product development environment for the customers, which can promote the efficiency of customer collaboration in product development. Moreover, it has influenced on the output function of the customers. Considering this incentive mode, we can adjust the output function of the $i$ th customer as $\pi^{\prime}\left(x_{i}\right)=\lambda_{p}\left(x_{p}\right)\left(e_{i}+\sum_{i \neq j} m_{j i}\right)+\varepsilon_{i}$. Let $F_{i}$ represents the economic incentive income of the $i$ th customer, and it can calculated as $F_{i}=s+\alpha \pi^{\prime}\left(x_{i}\right)+\beta \sum_{t=1}^{n} \pi^{\prime}\left(x_{t}\right)$. Meantime, let $\lambda_{p}\left(x_{p}\right)$ represents the output adjustment coefficient of the customer, and $x_{p}$ is the effort degree of the firm. Furthermore, $\lambda_{p}\left(x_{p}\right)$ is the function of the effort degree of the firm $x_{p}$, and complies with the law of diminishing marginal returns. The first one is the firm provides the product development platform, tools, the good environment, and training the customers. According to the second kind of incentive method, we convert this kind of spiritual incentive into the input for the customers. That is to say, the monetary equivalent income of the customer is $\frac{1}{2} \gamma\left(e_{i}+\sum_{i \neq j} m_{i j}\right)^{2}$, of which $\lambda>0$ is the pursuit coefficient of spiritual incentive of the customers.

Based on the above analysis, we determine the profit of the $i$ th customer:

$$
\omega_{i}=s+\alpha \pi^{\prime}\left(x_{i}\right)+\beta \sum_{t=1}^{n} \pi^{\prime}\left(x_{t}\right)+\frac{1}{2} \gamma\left(e_{i}+\sum_{i \neq j} m_{i j}\right)^{2}
$$

Suppose customers are risk averse, and have the same degree of risk aversion $\rho$. The Equation (2) presents the risk costs of the $i$ th customer according to the conclusion of Arrow-Pratt (Levy \& Levy, 2002).

$$
r_{i}=\rho\left(\frac{1}{2} \alpha^{2} \sigma^{2}+\frac{1}{2} n \beta^{2} \sigma^{2}\right)=\frac{1}{2} \rho \sigma^{2}\left(\alpha^{2}+n \beta^{2}\right)
$$

Therefore, the certainty equivalence of customers equals to remaining sum that profit subtracted from cost. 


$$
\begin{aligned}
U_{i}= & {\left[s+\alpha \pi^{\prime}\left(x_{i}\right)+\beta \sum_{t=1}^{n} \pi^{\prime}\left(x_{t}\right)+\frac{1}{2} \gamma\left(e_{i}+\sum_{i \neq j} m_{i j}\right)^{2}\right]-\left[\frac{1}{2} a e_{i}^{2}+\frac{1}{2} a \sum_{i \neq j} m_{i j}^{2}\right] } \\
& -\left[\frac{1}{2} \rho \sigma^{2}\left(\alpha^{2}+n \beta^{2}\right)\right] \\
= & s+\alpha \lambda_{p}\left(x_{p}\right)\left(e_{i}+\sum_{j \neq i} m_{j i}\right)+\beta \sum_{t=1}^{n} \lambda_{p}\left(x_{p}\right)\left(e_{t}+m_{t}\right)+\frac{1}{2} \gamma\left(e_{i}+\sum_{i \neq j} m_{i j}\right)^{2} \\
& -\frac{1}{2} a e_{i}^{2}-\frac{1}{2} a \sum_{i \neq j} m_{i j}^{2}-\frac{1}{2} \rho \sigma^{2}\left(\alpha^{2}+n \beta^{2}\right) \\
= & s+\left[\alpha \lambda_{p}\left(x_{p}\right)\left(e_{i}+\sum_{j \neq i} m_{j i}\right)-\frac{1}{2} \rho \alpha^{2} \sigma^{2}\right]+\left[\beta \sum_{t=1}^{n} \lambda_{p}\left(x_{p}\right)\left(e_{t}+m_{t}\right)-\frac{1}{2} n \rho \beta^{2} \sigma^{2}\right] \\
+ & \frac{1}{2} \gamma\left(e_{i}+\sum_{i \neq j} m_{i j}\right)^{2}-\left(\frac{1}{2} a e_{i}^{2}+\frac{1}{2} a \sum_{i \neq j} m_{i j}^{2}\right)
\end{aligned}
$$

In the Equation (3), the first item represents the fixed salary of the customer $i$. The second item $\alpha \lambda_{p}\left(x_{p}\right)\left(e_{i}+\sum_{j \neq i} m_{j i}\right)-\frac{1}{2} \rho \alpha^{2} \sigma^{2}$ is the certainty equivalence of the $i$ th customer's performance salary. The third item $\beta \sum_{t=1}^{n} \lambda_{p}\left(x_{p}\right)\left(e_{t}+m_{t}\right)-\frac{1}{2} n \rho \beta^{2} \sigma^{2}$ is the certainty equivalence of the $i$ th customer's team share. The fourth item $\frac{1}{2} \gamma\left(e_{i}+\sum_{i \neq j} m_{i j}\right)^{2}$ denotes the certainty equivalence of the $i$ th customer's spiritual incentive. The last item $\frac{1}{2} a e_{i}^{2}+\frac{1}{2} a \sum_{i \neq j} m_{i j}^{2}$ represents the certainty equivalence of the $i$ th customer's effort cost.

During the collaborative product development, customers are seek maximal self-utility by providing their own efforts and efforts to help other customers. That is mean maximizing $U_{i}$ (i.e. $\max U_{i}$ ). Therefore, we calculate the first order partial derivative of the $U_{i}$ with respect to $e_{i}$ and $m_{i j}$ and the result is:

$$
\left\{\begin{array}{l}
\frac{\partial U_{i}}{\partial e_{i}}=\alpha \lambda_{p}\left(x_{p}\right)+\beta \lambda_{p}\left(x_{p}\right)+\gamma\left(e_{i}+\sum_{i \neq j} m_{i j}\right)-a e_{i}=0 \\
\frac{\partial U_{i}}{\partial m_{i j}}=\beta \lambda_{p}\left(x_{p}\right)+\gamma\left(e_{i}+\sum_{i \neq j} m_{i j}\right)-a m_{i j}=0
\end{array}\right.
$$

Then the value of $e_{i}$ and $m_{i j}$ can be obtained by jointly solving the two formulas in the Equation (4).

$$
e_{i}=\frac{\alpha\left[\gamma \lambda_{p}\left(x_{p}\right)+a \lambda_{p}\left(x_{p}\right)-n \gamma \lambda_{p}\left(x_{p}\right)\right]+a \beta \lambda_{p}\left(x_{p}\right)}{a(a-n \gamma)}
$$




$$
m_{i j}=\frac{\gamma \alpha \lambda_{p}\left(x_{p}\right)+a \beta \lambda_{p}\left(x_{p}\right)}{a(a-n \gamma)}
$$

\subsection{The Firm's Objective}

During the process of customer collaboration in product development, the firm has to expend costs to motivate customers. The costs include two parts. The first part is the investment of the economic incentive and the spiritual incentive for the customers. The second part is the investment in the product development platform, customer training and other aspects. The total investment of the firm can be represented by $C_{p}=\sum_{i=1}^{n}\left[F_{i}+\frac{1}{2} \gamma\left(e_{i}+\sum_{i \neq j} m_{i j}\right)^{2}\right]+\frac{1}{2} v_{p} x_{p}^{2}$, of which $v_{p}$ is the effort cost coefficient of the firm. Supposing the firm is risk neutral, its certainty equivalence of is equal to expected profit and can be determined by using Equation (7).

$$
\begin{aligned}
U_{p}= & \sum_{i=1}^{n} \pi^{\prime}\left(x_{i}\right)-\sum_{i=1}^{n}\left[s+\alpha \pi^{\prime}\left(x_{i}\right)+\beta \sum_{t=1}^{n} \pi^{\prime}\left(x_{t}\right)+\frac{1}{2} \gamma\left(e_{i}+\sum_{i \neq j} m_{i j}\right)^{2}\right]-\frac{1}{2} v_{p} x_{p}^{2} \\
= & \sum_{i=1}^{n} \lambda_{p}\left(x_{p}\right)\left(e_{i}+\sum_{i \neq j} m_{j i}\right)-\frac{1}{2} v_{p} x_{p}^{2} \\
& -\sum_{i=1}^{n}\left[s+\alpha \lambda_{p}\left(x_{p}\right)\left(e_{i}+\sum_{i \neq j} m_{j i}\right)+\beta \sum_{t=1}^{n} \lambda_{p}\left(x_{p}\right)\left(e_{t}+m_{t}\right)+\frac{1}{2} \gamma\left(e_{i}+\sum_{i \neq j} m_{i j}\right)^{2}\right]
\end{aligned}
$$

Assume the retained income level of the $i$ th customer is $u_{0}$. This value reflects the possibility of customer collaboration in product development. If the certainty equivalence of a customer is lower than $u_{0}$, then this customer will not participate in product development. Therefore, if the $i$ th customer collaboration in product development, its certainty equivalence must satisfy the participation constraint, which denote as $I R$ :

$$
U_{i} \geq u_{0}
$$

Moreover, there are asymmetric information between customers and the firm. Customers may choose the low effort level in the case of them effort level not observed by the firm through using information superiority to improve their own profit. Therefore, the certainty equivalence of customers also satisfies the incentive compatibility constraint, which denote as $I C$.

$$
\max U_{i}
$$

Based on the above analysis, we determine the following model. 


$$
\max U_{p}
$$

s.t

$$
\begin{array}{ll}
(I R) & U_{i} \geq u_{0} \\
(I C) & \max U_{i}
\end{array}
$$

At the same time, the Equations (5) and (6) are put into the Equation (7). Then we can calculate the first order partial derivative of the firm's profit $U_{p}$ with respect to the performance salary coefficient $\alpha$ and team share coefficient $\beta$ as below:

$$
\begin{aligned}
& \frac{\partial U_{p}}{\partial \alpha}=\frac{n \lambda_{p}^{2}\left(x_{p}\right)}{a-n \gamma}-\frac{n \lambda_{p}^{2}\left(x_{p}\right)\left(\gamma+a-n \gamma+n \gamma^{2}-\gamma^{2}\right)}{a(a-n \gamma)^{2}} \alpha-\frac{a n \lambda_{p}^{2}\left(x_{p}\right)}{(a-n \gamma)^{2}} \beta-n \rho \alpha \sigma^{2} \\
& \frac{\partial U_{p}}{\partial \beta}=\frac{n^{2} \lambda_{p}^{2}\left(x_{p}\right)}{a-n \gamma}-\frac{a n \lambda_{p}^{2}\left(x_{p}\right)}{(a-n \gamma)^{2}} \alpha-\frac{a n^{2} \lambda_{p}^{2}\left(x_{p}\right)}{(a-n \gamma)^{2}} \beta-n^{2} \rho \beta \sigma^{2}
\end{aligned}
$$

The certainty equivalence of the firm is concave function, which is proving through an approach of Hesse Matrix (see appendix A). When $U_{p}$ is maximum, $\frac{\partial U_{p}}{\partial \alpha}$ and $\frac{\partial U_{p}}{\partial \beta}$ are equal to zero. Meanwhile, the performance salary coefficient $\alpha$ and team share coefficient $\beta$ achieve a balance. According to the Equation (12), we can get the following results. 


$$
\begin{aligned}
\alpha^{*}= & n^{2} \lambda_{p}^{2}\left(x_{p}\right)\left[a+\rho \sigma^{2}(a-n \gamma)^{2}\right]\left[2 a \gamma-n \gamma^{2}+(a-n \gamma)^{2}+a \rho \sigma^{2}\right] \\
& -\frac{n^{2} \lambda_{p}^{2}\left(x_{p}\right)(a-n \gamma)^{3} \rho \sigma^{2}}{a^{2}+\rho \sigma^{2}(a-n \gamma)^{2}} \\
\beta^{*}= & \left.\frac{\lambda_{p}^{2}\left(x_{p}\right)(a-n \gamma)}{a+\rho \sigma^{2}(a-n \gamma)^{2}} \cdot\left[\frac{a n \lambda_{p}^{2}\left(x_{p}\right)-a n^{2} \lambda_{p}^{2}\left(x_{p}\right)}{(a-n \gamma)^{2}}-n \rho \sigma^{2}\right)\right] \cdot \\
& {\left[\frac{\lambda_{p}^{2}\left(x_{p}\right)-a \rho \sigma^{2} \lambda_{p}^{2}\left(x_{p}\right)(a-n \gamma)^{2}}{n^{2}-a^{3}}\right] \cdot\left[\frac{a \lambda_{p}^{2}\left(x_{p}\right)+\rho \sigma^{2}(a-n \gamma)^{2}}{\lambda_{p}^{2}\left(x_{p}\right)\left(2 a \gamma-n \gamma^{2}\right)+\lambda_{p}^{2}\left(x_{p}\right)\left(a-n^{2} \gamma+a \rho \sigma^{2}\right)}\right] }
\end{aligned}
$$

We can get the optimal of the performance salary coefficient $\alpha$ and team share coefficient $\beta$. It can be seen from Equation (13), the optimal of $\alpha$ and $\beta$ are determined by the degree of risk aversion, the spiritual pursuit coefficient, the effort costs of the customer, and the wellness of product development environment.

\section{Analysis of the Influence of Incentive Factors}

In the Equation (5), $e_{i}$ represents the effort degree of the customer, reflecting enthusiasm of participating in product development. The greater $e_{i}$ is, the harder the customer collaborating in product development. In the Equation (6), $m_{i j}$ denotes as the effort degree of helping other customers, which shows the interaction between customers. $m_{i j}>0$ illustrates the mutual help and mutual promotion between customers, and vice versa, that means customers is in the relationship of mutual defeating. With the analysis of the economic incentive and non-economic incentive factors influence on the effort degree of helping other customers and the effort degree of the customer himself, we can determine their influence degree as well as how these factors influence on the enthusiasm of customer collaborating in product development.

\subsection{Basic Condition of Achieving Customer Collaboration}

The condition of the customer collaboration is $e_{i}>0$ and $m_{i j}>0$. According to the Equation (6),

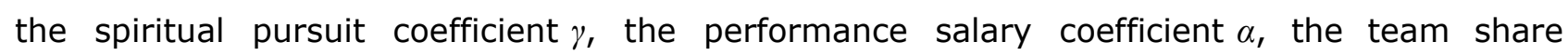
coefficient $\beta$, the output adjustment coefficient of the customer $\lambda_{p}\left(x_{p}\right)$, and the cost coefficient of the effort degree $\alpha$ are all positive values. Therefore, $(\gamma \alpha+\alpha \beta) \lambda_{p}\left(x_{p}\right)>0$. Moreover, there is $e_{i}>0, m_{i j}>0$ only under the condition of $a(a-n \gamma)>0$. Therefore, we can draw a conclusion that the basic condition of achieving customer collaboration is $a>n \gamma$. 


\subsection{The Incentive Function of the Fixed Salary}

As is shown in the Equation (5) and (6), there is irrelevant between the fixed salary $s$ and the effort degree of the customer and the effort degree of helping others. Therefore, the fixed salary, in the promotion of the effort degree of the customer, is without incentive effect, which is only for providing the basic safeguard for the customer in the collaboration of product development.

\subsection{The Incentive Function of the Performance Salary}

According to the Equation (5), we calculate the first order partial derivative of $e_{i}$ with respect to the performance salary coefficient $\alpha$ and the result is:

$$
\frac{\partial e_{i}}{\partial \alpha}=\frac{\lambda_{p}\left(x_{p}\right)(\gamma+a-n \gamma)}{a(a-n \gamma)}>0
$$

Therefore, the higher the performance salary is, the more the effort degree of the customer pays will be, and the higher the enthusiasm of customers collaborating in product development will be.

According to the Equation (6), we can determine the first order partial derivative of $m_{i j}$ with respect to the performance salary coefficient $\alpha$, and the result is as follows:

$$
\frac{\partial m_{i j}}{\partial \alpha}=\frac{\gamma \lambda_{p}\left(x_{p}\right)}{a(a-n \gamma)}>0
$$

We can draw a conclusion that the higher performance salary will contribute to the higher effort degree of the mutual help between customers. In general, the performance salary is not conducive to the cooperation among customers, and it will raise the degree of competition. However, the economic incentives proposed in this paper include the fixed salary, performance salary and team share. The coefficient of the performance salary increases, which will make the customer not only focus on his own efforts to enhance the level of the performance salary, but also pay attention to the collaboration with other customers. In this way, it can improve the product development performance of the whole innovation team to get more shares from the team. Ultimately, they can realize the maximization of their own interests.

Then, we minus the Equation (14) with the (15) as followings:

$$
\frac{\partial e_{i}}{\partial \alpha}-\frac{\partial m_{i j}}{\partial \alpha}=\frac{\lambda_{p}\left(x_{p}\right)(\gamma+a-n \gamma)-\gamma \lambda_{p}\left(x_{p}\right)}{a(a-n \gamma)}=\frac{\lambda_{p}\left(x_{p}\right)}{a}>0
$$


Therefore, we can draw a conclusion that the impact of the performance salary on the effort degree of customer himself is bigger than its impact on the effort degree of helping with each other.

\subsection{The Incentive Function of the Team Salary}

According to the Equation (5), we can calculate the first order partial derivative of $e_{i}$ with respect to the team share coefficient $\beta$, and the result is:

$$
\frac{\partial e_{i}}{\partial \beta}=\frac{a \lambda_{p}\left(x_{p}\right)}{a(a-n \gamma)}>0
$$

Therefore, the firm can effectively motivate customer to collaborating in product development in a more positive way by increasing the team share coefficient.

According to the Equation (6), we can calculate the first order partial derivative of $m_{i j}$ with respect to the team dividend coefficient $\beta$, and the result is as follows:

$$
\frac{\partial m_{i j}}{\partial \beta}=\frac{a \lambda_{p}\left(x_{p}\right)}{a(a-n \gamma)}>0
$$

In this way, in the process of customer collaborative product development, the higher team share coefficient will lead to the higher degree of mutual collaboration between customers.

Then, we minus the Equation (14) with (15) and can get following equation:

$$
\frac{\partial e_{i}}{\partial \beta}-\frac{\partial m_{i j}}{\partial \beta}=\frac{a \lambda_{p}\left(x_{p}\right)-a \lambda_{p}\left(x_{p}\right)}{a(a-n \gamma)}=0
$$

It illustrates that the team share has the same incentive effect on the improving the effort degree of the customer himself and the mutual help.

\subsection{The Incentive Effect of the Effort Degree of the Firm}

In order to enhance the performance of customer collaborative product development, the firm creates a favorable product development atmosphere, establish a product development platform, and provide tools for the customers. These factors provide good and convenient working environment for the customers in the process of product development, motivate customers' participation in product development, and improve the performance of product development. 
According to the Equation (5) and (6), we can calculate respectively the first order partial derivative of the output coefficient $\lambda_{p}\left(x_{p}\right)$ in the effort degree of the customer $e_{i}$ as well as the effort degree of helping other customers $m_{i j}$, and the results are as follow:

$$
\begin{aligned}
& \frac{\partial e_{i}}{\partial \lambda_{p}\left(x_{p}\right)}=\frac{\gamma+a-n \gamma}{a(a-n \gamma)} \alpha+\frac{1}{(a-n \gamma)} \beta>0 \\
& \frac{\partial m_{i j}}{\partial \lambda_{p}\left(x_{p}\right)}=\frac{\gamma}{a(a-n \gamma)} \alpha+\frac{1}{(a-n \gamma)} \beta>0
\end{aligned}
$$

Therefore, the effort degree of the firm is positive correlation with the effort degree of the customer, which proves the above mentioned.

\subsection{The Incentive Function of the Spiritual Incentive}

According to the Equation (5) and (6), we can calculate respectively the first order partial derivative of the spiritual pursuit coefficient $\gamma$ in the effort degree of the customer $e_{i}$ as well as the effort degree of helping other customers $m_{i j}$. The conclusion is as follows:

$$
\begin{aligned}
& \frac{\partial e_{i}}{\partial \gamma}=\frac{\lambda_{p}\left(x_{p}\right)}{a} \frac{\alpha n+\alpha \lambda_{p}\left(x_{p}\right)+(a-n \gamma) \alpha+a n \beta}{(a-n \gamma)^{2}}>0 \\
& \frac{\partial m_{i j}}{\partial \lambda_{p}\left(x_{p}\right)}=\frac{1+n \beta}{(a-n \gamma)^{2}}>0
\end{aligned}
$$

Thereby, the spiritual incentives to the customer, which including promoting the realization of self-value and self- satisfaction, and offering a certain degree of trust and care to the customer, can elevate the enthusiasm of the customer to participate in product development and to collaborate with other customers.

\section{Conclusion}

With the increasing competition in markets, firms which are subject to rapid changes of external environment need to develop new products better and faster than their competitors. These demands are what make the external resource so important, especially customers and their knowledge. It has been recognized that customer collaboration is of great importance in the development of products.

To motivate customer to collaborate in product development and improve their positivity and working efforts, the firm need to provide the appropriate incentives for customers who collaboration in product development. Current researches only propose some incentive factors 
but not analyze the mechanism and degree of these factors influence on customer's positivity. Aiming at this insufficiency, this paper proposes two incentive modes and analyze the influence of them on customers' positivity and working efforts quantitatively. The results as follow:

(1) Propose two incentive modes which including economic incentive and non-economic incentive. The fixed salary, performance salary, and team share are the main economic incentive factors. And the non-economic incentive factors include two main forms. The one is a good environment for the customers, including product development atmosphere, the product development platform of informationalization, product development tool and training. The second is spiritual motivation for the customers, including promoting the collaborative customers to realize self-value and self-satisfaction, offering priority of experience right in the new products and supporting the customers with trust and care by the enterprises.

(2) The fixed salary shows no motivational effect but basic guarantee.

(3) The performance salary not only promotes effort level within customers themselves, but also enhances collaboration among them. Moreover, it shows more influence on the former.

(4) The team share incentive affects both effort levels equally.

(5) The better spiritual incentive, the higher companies' effort level, the better innovative environment, and the more motivate customers' collaboration in product development.

(6) The incentive coefficient of collaborative customer's performance salary and team share are decided by the degree of risk aversion, the spiritual pursuit coefficient, the effort costs of the customer, and the wellness of product development environment.

\section{References}

Amabile, T.M., Conti, R., Coon, H., Lazenby, J., \& Herron, M. (1996). Assessing the work environment for creativity. Academy of management journal, 39(5), 1154-1184. http://dx.doi.org/10.2307/256995

Auriol, E., Friebel, G., \& Pechlivanos, L. (2002). Career concerns in teams. Journal of Labor Economics, 20(2), 289-307. http://dx.doi.org/10.1086/338240

Büyüközkan, G., \& Arsenyan, J. (2012). Collaborative product development: a literature overview. Production Planning \& Control, 23(1), 47-66.

http://dx.doi.org/10.1080/09537287.2010.543169 
Ba, S., Stallaert, J., \& Whinston, A.B. (2001). Research commentary: introducing a third dimension in information systems design-the case for incentive alignment. Information Systems Research, 12(3), 225-239. http://dx.doi.org/10.1287/isre.12.3.225.9712

Baldwin, C., Hienerth, C., \& Von Hippel, E. (2006). How user innovations become commercial products: A theoretical investigation and case study. Research Policy, 35(9), 1291-1313. http://dx.doi.org/10.1016/j.respol.2006.04.012

Bartl, M., Fuller, J., Muhlbacher, H., \& Ernst, H. (2012). A managers perspective on virtual customer integration for new product development. Journal of Product Innovation Management, 29(6), 1031-1046. http://dx.doi.org/10.1111/j.1540-5885.2012.00946.x

Brockhoff, K. (2003). Customers' perspectives of involvement in new product development. International Journal of Technology Management, 26(5), 464-481. http://dx.doi.org/10.1504/IJTM.2003.003418

Davenport, T.H., \& Prusak, L. (2000). Working knowledge: How organizations manage what they know. Harvard Business Press. http://dx.doi.org/10.1145/347634.348775

Füller, J. (2010). Refining virtual co-creation from a consumer perspective. California Management Review, 52(2), 98-122. http://dx.doi.org/10.1525/cmr.2010.52.2.98

Faems, D., Van Looy, B., \& Debackere, K. (2005). Interorganizational collaboration and innovation: toward a portfolio approach. Journal of product innovation management, 22(3), 238250. http://dx.doi.org/10.1111/j.0737-6782.2005.00120.x

Greer, C.R., \& Lei, D. (2012). Collaborative Innovation with Customers: A Review of the Literature and Suggestions for Future Research. International Journal of Management Reviews, 14(1), 63-84. http://dx.doi.org/10.1111/j.1468-2370.2011.00310.x

Holmstrom, B., \& Milgrom, P. (1987). Aggregation and linearity in the provision of intertemporal incentives. Econometrica: Journal of the Econometric Society, 5(2), 303-328. http://dx.doi.org/10.2307/1913238

Kaiser, S., \& Müller-Seitz, G. (2008). Leveraging lead user knowledge in software development -The case of weblog technology. Industry and Innovation, 15(2), 199-221.

http://dx.doi.org/10.1080/13662710801954542

Kausch, C. (2007). A risk-benefit perspective on early customer integration. Springer.

Levy, H., \& Levy, M. (2002). Arrow-Pratt risk aversion, risk premium and decision weights. Journal of Risk and Uncertainty, 25(3), 265-290. http://dx.doi.org/10.1023/A:1020928022557 
Lin, H.-F. (2007). Knowledge sharing and firm innovation capability: an empirical study. International Journal of Manpower, 28(3/4), 315-332. http://dx.doi.org/10.1108/01437720710755272

Miotti, L., \& Sachwald, F. (2003). Co-operative R\&D: why and with whom?: An integrated framework of analysis. Research Policy, 32(8), 1481-1499. http://dx.doi.org/10.1016/S00487333(02)00159-2

Nieto, M.J., \& Santamaría, L. (2007). The importance of diverse collaborative networks for the novelty of product innovation. Technovation, 27(6), 367-377.

http://dx.doi.org/10.1016/j.technovation.2006.10.001

Vargo, S.L., \& Lusch, R.F. (2004). Evolving to a new dominant logic for marketing. Journal of marketing, 68(1), 1-17. http://dx.doi.org/10.1509/jmkg.68.1.1.24036

Von Hippel, E. (2005). Democratizing innovation. MIT press.

Wei, G.-X., Yu, L.-A., Wang, S.-Y., \& Lai, K.K. (2007). Study on Incentive Factors of Team Cooperation based on Synergy Effect. Systems Engineering-Theory \& Practice, 27(1), 1-9. http://dx.doi.org/10.1016/S1874-8651(08)60007-1

Yu, G., Yu, Y., Xing, Q., \& Li, F. (2014). Research on the time optimization model algorithm of Customer Collaborative Product Innovation. Journal of Industrial Engineering and Management, 10(1),137-152. http://dx.doi.org/10.3926/jiem.2010.v10n1.p137-152

Yang, Y., Guo, B., Yin, S., Wang, W.-L., \& Zhang, X.-D. (2008). Connotation, theory framework and application of customer collaborative innovation. Computer Integrated Manufacturing Systems, 14(5), 449-059.

Zhang, L.-B., \& Zhang, G.-X. (2012). The App Store Model of Apple Based on the Theory of Two-Sided Markets. Computer Engineering \& Science, 34(4), 188-192. 


\section{Appendix}

Proofs of the certainty equivalence of the firm $U_{p}$ are concave function.

If we prove the Hesse Matrix of $U_{p}$ with respect to $\alpha$ and $\beta$ is negative definite matrix, then prove $U_{p}$ is concave function.

The Hesse Matrix of $U_{p}$ with respect to $\alpha$ and $\beta$ is:

$$
\left|U_{p}\right|=\left[\begin{array}{cc}
\frac{\partial^{2} U_{p}}{\partial^{2} \alpha} & \frac{\partial^{2} U_{p}}{\partial \alpha \partial \beta} \\
\frac{\partial^{2} U_{p}}{\partial \beta \partial \alpha} & \frac{\partial^{2} U_{p}}{\partial^{2} \beta}
\end{array}\right]=\left[\begin{array}{cc}
-\frac{n \lambda_{p}^{2}\left(x_{p}\right)\left(\gamma+a-n \gamma+n \gamma^{2}-\gamma^{2}\right)}{a(a-n \gamma)^{2}}-n \rho \sigma^{2} & \frac{a n \lambda_{p}^{2}\left(x_{p}\right)}{(a-n \gamma)^{2}} \\
\frac{a n \lambda_{p}^{2}\left(x_{p}\right)}{(a-n \gamma)^{2}} & \frac{a n^{2} \lambda_{p}^{2}\left(x_{p}\right)}{(a-n \gamma)^{2}}-n^{2} \rho \sigma^{2}
\end{array}\right]
$$

According to the negative definite judgment criteria of Hesse Matrix, the first order master type of $\left|U_{p}\right|$ as follows:

$$
\begin{aligned}
\frac{\partial^{2} U_{p}}{\partial^{2} \alpha} & =-\frac{n \lambda_{p}^{2}\left(x_{p}\right)\left(\gamma+a-n \gamma+n \gamma^{2}-\gamma^{2}\right)}{a(a-n \gamma)^{2}}-n \rho \sigma^{2} \\
& =-\frac{n \lambda_{p}^{2}\left(x_{p}\right)\left[(\gamma+a-n \gamma)^{2}+n(n-1) \gamma^{2}\right]}{a(a-n \gamma)^{2}}-n \rho \sigma^{2}<0
\end{aligned}
$$

The second order master type of $\left|U_{p}\right|$ is:

$$
\begin{gathered}
\left|U_{p}\right|=\frac{n^{3} \lambda_{p}^{4}\left(x_{p}\right)}{(a-n \gamma)^{4}}\left\{\left[\frac{(a-n \gamma)^{2}+2 a \gamma-n \gamma^{2}}{a}+\frac{\rho \sigma^{2}(a-n \gamma)^{2}}{\lambda_{p}^{2}\left(x_{p}\right)}\right]\left[a+\frac{\rho \sigma^{2}(a-n \gamma)^{2}}{\lambda_{p}^{2}\left(x_{p}\right)}\right]-\frac{a^{2}}{n}\right\} \\
\frac{(a-n \gamma)^{2}+2 a \gamma-n \gamma^{2}}{a}=\frac{a^{2}-2 a n \gamma+n^{2} \gamma^{2}+2 a \gamma-n \gamma^{2}}{a}
\end{gathered}
$$

Because $=a-2 n \gamma+\frac{n^{2} \gamma^{2}}{a}+2 \gamma-\frac{n \gamma^{2}}{a}$

$=a-(n-1) \gamma\left(2-\frac{n \gamma}{a}\right)<a$

therefore, $\left[\frac{(a-n \gamma)^{2}+2 a \gamma-n \gamma^{2}}{a}+\frac{\rho \sigma^{2}(a-n \gamma)^{2}}{\lambda_{p}^{2}\left(x_{p}\right)}\right]\left[a+\frac{\rho \sigma^{2}(a-n \gamma)^{2}}{\lambda_{p}^{2}\left(x_{p}\right)}\right]$

$$
>\left[\frac{(a-n \gamma)^{2}+2 a \gamma-n \gamma^{2}}{a}+\frac{\rho \sigma^{2}(a-n \gamma)^{2}}{\lambda_{p}^{2}\left(x_{p}\right)}\right]^{2}
$$


To prove $\left|U_{p}\right|>0$, we need prove $\left[\frac{(a-n \gamma)^{2}+2 a \gamma-n \gamma^{2}}{a}+\frac{\rho \sigma^{2}(a-n \gamma)^{2}}{\lambda_{p}^{2}\left(x_{p}\right)}\right]^{2}-\frac{a^{2}}{n}>0$, that is proving $\left[\frac{(a-n \gamma)^{2}+2 a \gamma-n \gamma^{2}}{a}+\frac{\rho \sigma^{2}(a-n \gamma)^{2}}{\lambda_{p}^{2}\left(x_{p}\right)}\right]>\frac{a}{\sqrt{n}}$.

Because $\frac{(a-n \gamma)^{2}+2 a \gamma-n \gamma^{2}}{a}-\frac{a}{\sqrt{n}}=\frac{(\sqrt{n}-1) a^{2}+(n-1)\left(2 a \gamma+n \gamma^{2}\right)}{a \sqrt{n}}>0$, so $\left|U_{p}\right|>0$.

Therefore, we determine the Hesse Matrix is the negative definite matrix, which illustrates the certainty equivalence of the firm $U_{p}$ is concave function.

Journal of Industrial Engineering and Management, 2015 (www.jiem.org)

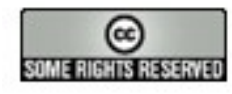

Article's contents are provided on an Attribution-Non Commercial 3.0 Creative commons license. Readers are allowed to copy, distribute and communicate article's contents, provided the author's and Journal of Industrial Engineering and Management's names are included. It must not be used for commercial purposes. To see the complete license contents, please visit http://creativecommons.org/licenses/by-nc/3.0/. 